\title{
ARRoz-Vermelho (Oryza sativa) Resistente aOs Herbicidas IMIDAZOLINONAS ${ }^{1}$
}

\author{
Red Rice (Oryza sativa) Resistant to the Herbicides Imidazolinones \\ MENEZES, V.G. ${ }^{2}$, MARIOT, C.H.P. ${ }^{2}$, KALSING, A. ${ }^{3}$ e GOULART, I.C.G.R. ${ }^{3}$
}

\begin{abstract}
RESUMO - O desenvolvimento de genótipos comerciais de arroz resistentes a herbicidas do grupo químico das imidazolinonas proporcionou uma ferramenta eficaz para o controle seletivo do arroz-vermelho (Oryza sativa) em cultivo de arroz irrigado. Contudo, o uso continuo dessa tecnologia pode favorecer o desenvolvimento de populações de arroz-vermelho resistentes aos herbicidas utilizados para o seu controle. Objetivou-se com este trabalho avaliar a ocorrência de populações de arroz-vermelho resistentes aos herbicidas imidazolinonas, por meio de curvas de dose-resposta, através do fator de resistência (FR). Populações de arrozvermelho não controladas (escapes) advindas de lavouras de arroz cultivado no sistema Clearfield $^{\circledR}$ no Estado do Rio Grande do Sul foram avaliadas em casa de vegetação na sua sensibilidade ao herbicida Only (imazethapyr + imazapic - $75+25 \mathrm{~g} \mathrm{~L}^{-1}$ ). O resultado de resposta às doses do herbicida confirma a resistência em 56\% das populações de arrozvermelho, as quais podem ser agrupadas em baixo $(F R=5,2)$ e alto $(F R=11,6)$ niveis de resistência às imidazolinonas.
\end{abstract}

Palavras-chave: arroz cultivado (Oryza sativa), cv. IRGA 422 CL, herbicida Only.

\begin{abstract}
The development of commercial rice genotypes resistant to herbicides of the imidazolinone chemical group has proved to be an effective method for the selective control of red rice (Oryza sativa) in flooded rice culture. However, the continued use of this technology led to the development of populations of red rice resistant to the herbicides used in their control. The objective of this study was to evaluate the occurrence of resistance in red rice populations by dose response curves through level of resistance (LR). Non-controlled populations of red rice from rice fields cultivated under the Clearfield System in the state of Rio Grande do Sul were evaluated under greenhouse conditions in relation to their sensitivity to the herbicide Only (imazethapyr + imazapic - $75+25 \mathrm{~g} \mathrm{~L}^{-1}$ ). The dose response result confirms that $56 \%$ of the red rice populations are resistant and that they can be grouped according to low $(F R=5.2)$ and high $(F R=11.6)$ levels of resistance to the herbicides imidazolinones.
\end{abstract}

Keywords: rice crop (Oryza sativa), cv. IRGA 422 CL, herbicide Only.

\section{INTRODUÇÃO}

O desenvolvimento do Sistema de Produção Clearfield $^{\circledR}$ (Basf, 2004) em arroz (Oryza sativa) cultivado proporcionou uma estratégia de manejo eficaz no controle seletivo de plantas daninhas, pelo uso de genótipos resistentes a herbicidas do grupo químico das imidazolinonas. O mecanismo de ação desses herbicidas é a inibição da atividade das enzimas acetolactato sintase (ALS) e aceto-hidroxi sintase (AHAS) na rota de sintese dos aminoácidos de cadeia ramificada valina, leucina e isoleucina (Rizzardi et al., 2004).

Recebido para publicação em 12.1.2009 e na forma revisada em 11.12.2009.

2 Engo-Agro-., M.Sc., Pesquisador do Instituto Rio Grandense do Arroz - IRGA, Divisão de Pesquisa, Avenida Bonifácio Carvalho Bernardes, 꾸 1.494, Caixa Postal 29, 94930-030 Cachoeirinha-RS, <vmgaedke@yahoo.com.br>; ${ }^{3}$ EngํAgro ${ }^{\circ}$, Alunos de Mestrado do Programa de Pós-Graduação em Fitotecnia, Universidade Federal do Rio Grande do Sul - UFRGS, Caixa Postal 15100, 91501-970 Porto Alegre-RS. 
O principal propósito do uso de genótipos de arroz resistentes aos herbicidas refere-se ao controle seletivo do arroz-vermelho (O. sativa), que se destaca como a espécie daninha que causa maiores danos à cultura do arroz irrigado, em decorrência da redução da produtividade, da depreciação do produto final, das dificuldades de controle e do elevado grau de infestação das áreas cultivadas (Menezes et al., 2003). O controle químico eficaz do arrozvermelho não era possível com o uso de genótipos convencionais, por haver similaridade morfológica e fisiológica entre o arroz cultivado e a espécie daninha.

Ao uso do sistema Clearfield ${ }^{\circledR}$ é atribuída parte do incremento de produtividade da lavoura de arroz irrigado no Estado do Rio Grande do Sul nos últimos anos; até hoje, essa pode ser considerada a mais importante ferramenta disponibilizada aos produtores para controle químico do arroz-vermelho. Nesse contexto, mesmo com a crise mundial no setor de alimentos, o Estado do Rio Grande do Sul assume papel de relevância como produtor de arroz. A cada ano esse Estado está mais competitivo diante de países do Mercosul, como Argentina, Paraguai e Uruguai, e mesmo perante outros Estados brasileiros, como Mato Grosso e Santa Catarina. Atualmente, o Estado do Rio Grande do Sul é responsável por cerca de $60 \%$ da produção do Brasil e por $50 \%$ da produção do Mercosul, com área cultivada de aproximadamente 1.060.000 hectares, dos quais 500.000 estão sob o sistema Clearfield ${ }^{\circledR}$ (IRGA, 2008).

Apesar de proporcionar grande vantagem para a cultura do arroz, a adoção de genótipos resistentes a herbicidas implica a observação de aspectos relacionados à seleção de populações de arroz-vermelho resistentes. Todas as populações de plantas daninhas, independentemente da aplicação de qualquer produto, provavelmente contêm plantas resistentes a herbicidas (Kissmann, 1996), em especial as populações de arroz silvestre (Gealy et al., 2003; Rajguru et al., 2005; Burgos et al., 2005), em virtude da elevada diversidade genética da espécie $O$. sativa. Trabalho conduzido por Kuk et al. (2008) corrobora essa hipótese, demonstrando a existência de biótipos de arroz-vermelho tolerantes aos herbicidas imidazolinonas em áreas não agrícolas nos Estados Unidos.
Nessa ótica, fica evidente que o uso contínuo do sistema Clearfield ${ }^{\circledR}$ nas áreas de arroz irrigado do Rio Grande do Sul pode favorecer o desenvolvimento de populações de arroz-vermelho resistentes aos herbicidas imidazolinonas, devido ao uso repetido de herbicidas de um mesmo grupo ou pertencentes a diferentes grupos, mas com o mesmo mecanismo de ação.

Outro fato relevante que pode contribuir para a ocorrência de populações de arrozvermelho resistentes a herbicidas refere-se ao fluxo de genes entre arroz cultivado e arrozvermelho. A introdução de cultivares de arroz resistentes aos herbicidas imidazolinonas pode resultar na ocorrência de fluxo gênico para os genótipos de arroz silvestre (Burgos et al., 2005). A maioria dos trabalhos publicados sobre dispersão de pólen indica que as taxas de fecundação entre arroz cultivado e arrozvermelho ocorrem em niveis inferiores a $1 \%$ (Gealy et al., 2003; Burgos et al., 2005; Shivrain et al., 2007). Em estudos realizados no Estado do Rio Grande do Sul, Ramírez (2003) e Villa et al. (2006) encontraram fluxo gênico nas taxas de 0,042 e 0,065\%, respectivamente. Cabe ressaltar que pequenas taxas de fluxo gênico podem representar considerável aumento na frequência de indivíduos resistentes na população, em virtude do elevado grau de infestação das áreas cultivadas. Estudo demonstra que o fluxo gênico na taxa de $0,008 \%$ originou 170 individuos resistentes de arroz-vermelho por hectare (Shivrain et al., 2007).

Considerando a ocorrência de falhas no controle (escapes) de arroz-vermelho e o uso frequente de sementes contaminadas com grãos de arroz-vermelho pelos agricultores, em lavouras comerciais de arroz irrigado conduzidas sob o sistema Clearfield ${ }^{\circledR}$, objetivou-se com o presente trabalho avaliar a ocorrência de populações de arroz-vermelho resistentes aos herbicidas do grupo químico das imidazolinonas no Estado do Rio Grande do Sul, bem como o fator de resistência das populações por meio de curvas de dose-resposta, utilizando o fator de resistência.

\section{MATERIAL E MÉTODOS}

O ensaio foi conduzido em casa de vegetação na Estação Experimental do Arroz (EEA), 
pertencente ao Instituto Rio Grandense do Arroz (IRGA), localizada em Cachoeirinha-RS. O trabalho contou com o apoio de 39 Núcleos de Assistência e Extensão Rural (NATEs) do IRGA para coleta de material em campo e posterior envio ao local de condução do ensaio. Para otimizar a logística do trabalho com grande volume de material coletado, o ensaio foi conduzido em duas etapas, descritas a seguir.

Na primeira etapa, utilizaram-se 228 populações de arroz-vermelho provenientes de plantas não controladas (escapes) em lavouras comerciais do cultivar IRGA 422CL com dois a três anos de cultivos consecutivos. Cada população conteve sementes de panículas de diversas plantas que ocorriam no local de coleta em questão; nesse caso, cada população pode conter mais de um biótipo de arrozvermelho. Os cultivares comerciais de arroz IRGA 417 e Puitá INTA CL foram utilizados como controles sensivel e resistente, respectivamente. Lotes de 100 sementes foram semeados em bandejas com capacidade para $10 \mathrm{~L}$, contendo como substrato solo adubado conforme as recomendações técnicas da pesquisa para a cultura do arroz irrigado na região Sul do Brasil (SOSBAI, 2007). Cada recipiente acondicionou sementes de seis populações de arroz-vermelho e dos cultivares controle (suscetivel e resistente), semeadas de forma linear, com espaçamento entre linhas de $15 \mathrm{~cm}$. Diariamente, no início da manhã e no fim da tarde, as plantas foram irrigadas à capacidade de campo do solo. Quando as plantas atingiram o estádio V3 (Counce et al., 2000), foram aspergidas com o herbicida Only (imazethapyr + imazapic - $75+$ $25 \mathrm{~g} \mathrm{~L}^{-1}$ ) na dose de $1,2 \mathrm{~L}$ p.c. ha- ${ }^{-1}$. Adicionou-se adjuvante à calda herbicida na concentração de $0,5 \%$. A aplicação foi feita com pulverizador portátil de precisão pressurizado por gás carbônico, com barra de aplicação munida de pontas em leque modelo DG Teejet 110.015, e volume de calda aplicado equivalente a $150 \mathrm{~L} \mathrm{ha}^{-1}$. Avaliou-se a fitointoxicação causada pelo herbicida aos 14, 21 e 28 dias após a aplicação (DAA), adotando-se escala visual, em que a ausência de injúria correspondeu a $0 \%$ e a morte das plantas, a 100\% (EWRC, 1964).

Na segunda etapa, utilizaram-se apenas as populações selecionadas como resistentes na fase anterior, avaliando o fator de resistência (FR) pelas curvas de dose-resposta. O critério utilizado para selecionar as populações foi a fitointoxicação aos 28 DAA inferior ao valor de $50 \%$. As condições de cultivo das plantas e aplicação dos tratamentos foram similares às da etapa anterior. Os tratamentos constaram da combinação fatorial entre as populações de arroz-vermelho e seis doses do herbicida Only (L p.c. ha ${ }^{-1}$ ): 0,25, 0,5, 1,0, 2,0, 4,0 e testemunha sem aplicação. As avaliações de fitointoxicação causada pelo herbicida foram similares às da etapa anterior. Após a última avaliação, colheu-se a parte aérea das plantas, para determinação da biomassa seca. Para isso, o material vegetal foi submetido à secagem em estufa à temperatura de $60^{\circ} \mathrm{C}$, até atingir peso constante.

O delineamento experimental foi o de blocos ao acaso, com quatro repetições. Os dados de eficácia das doses do herbicida no controle das populações de arroz-vermelho foram submetidos à análise de variância, e as médias dos tratamentos, quando detectadas diferenças significativas, foram comparadas pelo teste de Duncan a 5\% de significância. Posteriormente, realizou-se o ajuste das curvas de dose-resposta que melhor representassem a população sensivel e as populações de arroz-vermelho resistentes, com auxílio do programa computacional Sigmaplot 9.0. A partir das equações das curvas de doseresposta determinou-se o $\mathrm{GR}_{50}$, ou seja, o valor que representa a dose necessária para obter $50 \%$ de fitointoxicação ou para reduzir em 50\% a massa seca da população sensivel e das populações resistentes. $O$ fator de resistência $(F R)$ foi calculado pelo quociente entre o $G_{50}$ das populações resistentes e o $\mathrm{GR}_{50}$ da população sensivel (Vidal et al., 2006).

\section{RESULTADOS E DISCUSSÃO}

Na primeira etapa, as populações de arrozvermelho apresentaram níveis distintos de sensibilidade na dose de 1,2 L p.c. ha-1 do herbicida Only. Na avaliação realizada aos 28 DAA, cerca de $56 \%$ das populações de arrozvermelho apresentaram valores de fitointoxicação inferiores aos do critério de seleção (Tabela 1). Ademais, na mesma avaliação, a fitointoxicação variou entre as populações advindas das distintas regiões orizícolas do 
Tabela 1 - Percentual de populações de arroz-vermelho (Oryza sativa) resistentes aos herbicidas imidazolinonas nas seis regiões orizícolas do Estado do Rio Grande do Sul. EEA/IRGA, Cachoeirinha-RS. 2008

\begin{tabular}{|l|c|c|c|}
\hline \multirow{2}{*}{ Região orizícola } & \multicolumn{2}{|c|}{$\begin{array}{c}\text { População de } \\
\text { arroz-vermelho }\end{array}$} & \multirow{2}{*}{$\begin{array}{c}\text { Resistência } \\
\text { (\%) }\end{array}$} \\
\cline { 2 - 3 } & Coletada & Resistente $^{1 /}$ & \\
\hline Campanha & 35 & 27 & 78 \\
\hline Depressão Central & 82 & 56 & 68 \\
\hline Fronteira Oeste & 22 & 10 & 45 \\
\hline Planície Costeira Externa & 23 & 13 & 56 \\
\hline Planície Costeira Interna & 38 & 12 & 32 \\
\hline Zona Sul & 28 & 10 & 36 \\
\hline \multicolumn{1}{|c|}{ Total } & 228 & 128 & 56 \\
\hline
\end{tabular}

1/ Populações resistentes apresentaram controle inferior a $50 \%$ aos 28 dias após a aplicação (DAA) dos herbicidas.

Estado do Rio Grande do Sul. A Depressão Central e a Fronteira Oeste apresentaram 78 e $68 \%$, respectivamente, das populações de arroz-vermelho com valor de fitointoxicação menor que $50 \%$ na dose de $1,2 \mathrm{~L}$ p.c. ha ${ }^{-1}$ de Only. Nas demais regiões esse percentual variou entre 32 e $56 \%$. Convém ressaltar que cada população conteve sementes de panículas de diversas plantas que ocorriam no local de coleta em questão. Dessa forma, a variabilidade genética entre as populações de arrozvermelho permitiu que certas populações sobrevivessem à exposição ao herbicida.

A caracterização de uma espécie daninha como resistente a um herbicida implica que, quando o produto foi introduzido e o rótulo desenvolvido, a maioria dos indivíduos em todas as populações dessa espécie era sensivel ao herbicida (Vidal et al., 2007). Nesse sentido, a falta de controle de parte das populações avaliadas foi atribuída à resistência ao herbicida Only, pois as plantas sobreviveram a uma dose $20 \%$ superior àquela que tipicamente proporciona controle eficaz do arroz-vermelho em áreas agrícolas.

Na segunda etapa, a população sensivel e as populações resistentes demonstraram distintos niveis de sensibilidade às doses crescentes do herbicida Only. Nas avaliações de fitointoxicação realizadas aos 14 e aos 21 DAA não ocorreu interação entre as populações resistentes de arroz-vermelho e, por isso, os resultados apresentados referem-se à média das 128 populações de arroz-vermelho selecionadas na primeira fase do ensaio (Tabela 2). Observa-se que a população sensivel foi controlada eficazmente pela dose recomendada para controle do arroz-vermelho em áreas agrícolas (1,0 L p.c. ha-1), e aos 14 DAA a fitointoxicação era superior a $90 \%$ nesse tratamento. No entanto, na mesma avaliação, a fitointoxicação das populações de arroz-vermelho resistentes foi de apenas $11 \%$ para o mesmo tratamento (Tabela 2).

$\mathrm{Na}$ avaliação realizada aos 21 DAA, a fitointoxicação aumentou com o incremento da dose do herbicida, porém com distintas magnitudes entre a população sensivel e as populações resistentes. A aplicação da maior dose do herbicida Only (4,0 L p.c. ha $\left.{ }^{-1}\right)$ controlou $100 \%$ da população sensivel. Por outro lado, as populações resistentes manifestaram sintomas de fitointoxicação da ordem de $76 \%$ aos 21 DAA (Tabela 1). Resultados semelhantes foram encontrados por Kuk et al. (2008), que obtiveram controle menor que $80 \%$ em populações tolerantes de arroz-vermelho com doses de imazethapyr quatro vezes superiores às doses recomendadas em lavouras, em avaliação realizada aos 20 DAA. Esses resultados indicam a condição de resistência das populações de arroz-vermelho avaliadas na segunda

Tabela 2 - Fitointoxicação em população de arroz cultivado (Oryza sativa) sensível (IRGA 417) e populações resistentes de arroz-vermelho (O. sativa) aos herbicidas imidazolinonas em função de doses do herbicida Only (imazethapyr + imazapic - $75+25 \mathrm{~g} \mathrm{~L}^{-1}$ ), aos 14 e 21 dias após a aplicação dos tratamentos (DAA). EEA/IRGA, Cachoeirinha-RS. 2008

\begin{tabular}{|c|c|c|c|c|c|}
\hline \multirow{2}{*}{ Tratamento } & \multirow{2}{*}{$\begin{array}{c}\text { Dose } \\
\text { (L.c. ha }\end{array}$} & \multicolumn{4}{|c|}{ Fitointoxicação (\%) } \\
\cline { 3 - 6 } & & \multicolumn{2}{|c|}{ População sensível } & \multicolumn{2}{|c|}{$\begin{array}{c}\text { População } \\
\text { resistente }{ }^{1 /}\end{array}$} \\
\cline { 3 - 6 } & & $14 \mathrm{DAA}^{2} /$ & $21 \mathrm{DAA}$ & $14 \mathrm{DAA}$ & $21 \mathrm{DAA}$ \\
\hline Testemunha & --- & $0 \mathrm{~d}^{*}$ & $0 \mathrm{~d}$ & $0 \mathrm{e}$ & $0 \mathrm{e}$ \\
\hline Only & 0,25 & $13 \mathrm{c}$ & $28 \mathrm{c}$ & $1 \mathrm{e}$ & $2 \mathrm{e}$ \\
\hline Only & 0,50 & $34 \mathrm{~b}$ & $58 \mathrm{~b}$ & $5 \mathrm{de}$ & $6 \mathrm{de}$ \\
\hline Only & 1,00 & $94 \mathrm{a}$ & $97 \mathrm{a}$ & $11 \mathrm{c}$ & $14 \mathrm{c}$ \\
\hline Only & 2,00 & $95 \mathrm{a}$ & $98 \mathrm{a}$ & $27 \mathrm{~b}$ & $50 \mathrm{~b}$ \\
\hline Only & 4,00 & $98 \mathrm{a}$ & $100 \mathrm{a}$ & $52 \mathrm{a}$ & $76 \mathrm{a}$ \\
\hline
\end{tabular}

${ }^{1 /}$ Valores referentes às médias das populações de arroz-vermelho resistentes $(\mathrm{n}=128)$; ${ }^{2} /$ Dias após a aplicação dos tratamentos; * Médias seguidas pela mesma letra na coluna não diferem entre si pelo teste de Duncan a $5 \%$ de probabilidade. 
fase do trabalho, possivelmente selecionadas pelo uso frequente e repetido do herbicida Only nas áreas orizícolas conduzidas sob o sistema Clearfield $\mathbb{R}$ no Estado do Rio Grande do Sul. Assim, este trabalho relata o primeiro caso de resistência do arroz-vermelho a herbicidas do grupo das imidazolinonas.

Para a fitointoxicação avaliada aos 28 DAA, houve interação entre as populações de arroz-vermelho resistentes, as quais foram agrupadas em função do fator de resistência ao herbicida, com base na classificação proposta por Vidal et al. (2007). Assim, 124 populações formaram um grupo caracterizado por baixo nível de resistência, e quatro populações formaram um grupo caracterizado por alto nivel de resistência.

Na Figura 1, observa-se que a aplicação de Only nas doses de 1,0 e 2,0 L do p.c. ha ${ }^{-1}$ proporcionou controle eficaz (98\%) da população sensivel, enquanto as populações com baixo nivel de resistência apresentaram controles de 15 e $68 \%$, respectivamente. As populações com alto nivel de resistência, por sua vez, mostraram controles de 3 e $12 \%$, respectivamente. A maior dose de aplicação de Only (4,0 L do p.c. ha $\mathrm{h}^{-1}$ ) apresentou total controle sobre a população sensivel, aos 28 DAA, enquanto as populações de arroz-vermelho resistentes com baixo nível de resistência apresentaram elevado controle (96\%). Já as populações de arroz-vermelho com alto nivel de resistência mostraram controle moderado (57\%), aos 28 DAA, para o mesmo tratamento.

Os resultados da produção de biomassa da parte aérea das plantas de arroz-vermelho estão de acordo com os valores obtidos nas avaliações de fitointoxicação, em que o incremento da dose do herbicida Only causou menores injúrias sobre as populações resistentes em relação à população sensível (Figura 2). As populações de arroz-vermelho com baixo e alto niveis de resistência apresentaram, respectivamente, fatores de resistência de 5,2 e 11,6 para a variável fitointoxicação e de 4,2 e 7,7 para a variável biomassa da parte aérea.

Os resultados permitem concluir que existem populações resistentes de arrozvermelho aos herbicidas imidazolinonas em lavouras de arroz irrigado conduzidas sob o

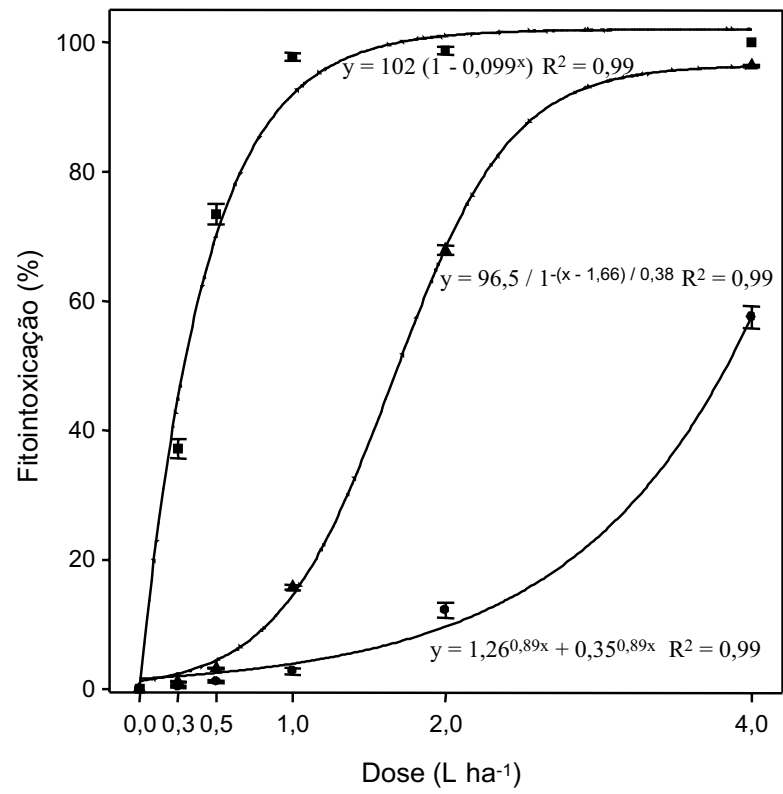

Figura 1 - Fitointoxicação em população de arroz cultivado (Oryza sativa) sensível (IRGA 417) (ם) e populações de arroz-vermelho $(O$. sativa $)$ com baixo $(\mathbf{A})(\mathrm{n}=124)$ e alto (O) $(\mathrm{n}=4)$ níveis de resistência a herbicidas imidazolinonas em função de doses do herbicida Only (imazethapyr + imazapic - $75+25 \mathrm{~g} \mathrm{~L}^{-1}$ ), aos 28 dias após aplicação dos tratamentos (DAA). EEA/IRGA, Cachoeirinha-RS. 2008.

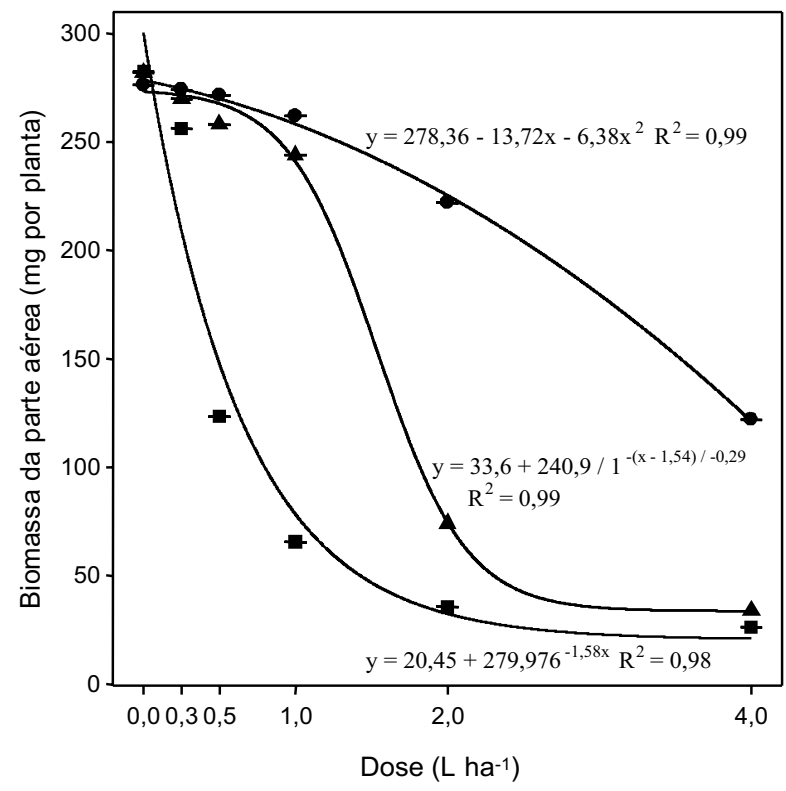

Figura 2 - Biomassa da parte aérea (mg por planta) em população de arroz (Oryza sativa) sensível (IRGA 417) (ם) e populações de arroz-vermelho $(O$. sativa) com baixo $(\mathbf{A})$ $(\mathrm{n}=124)$ e alto $(\mathbf{O})(\mathrm{n}=4)$ níveis de resistência a herbicidas imidazolinonas em função de doses do herbicida Only (imazethapyr + imazapic - $75+25 \mathrm{~g} \mathrm{~L}^{-1}$ ), aos 28 dias após aplicação dos tratamentos (DAA). EEA/IRGA, Cachoeirinha-RS. 2008 
sistema Clearfield $^{\circledR}$ em todas as seis regiões orizícolas do Estado do Rio Grande do Sul. Essas populações podem ser agrupadas em baixo e alto niveis de resistência aos herbicidas desse grupo em função do seu fator de resistência.

\section{AGRADECIMENTOS}

Os autores agradecem a todos os técnicos dos Núcleos de Assistência e Extensão Rural (NATEs), do Instituto Rio Grandense do Arroz (IRGA), que participaram das coletas das amostras de sementes para realização do presente trabalho.

\section{LITERATURA CITADA}

BASF BRASILEIRA. Sistema Clearfield de Produção 2004. Disponível em: http://agro.basf.com.br/hotsites/ clearfield/clearfield_arroz/cleararroz.asp?area $=3$. Acesso em: 20 de jun. de 2008.

BURGOS, N. R. et al. Outcrossing potential of Clearfield ${ }^{\mathrm{TM}}$ rice varieties with red rice. In: NORMAN, R. J.; JOHNSTON, T. H. Wells rice research studies Fayetteville: University of Arkansas Agriculture Experiment Station, 2005. p. 103-109.

COUNCE, P. A.; KEISLING, T. C. A uniform, objective, and adaptive system for expressing rice development. Crop Sci., v. 40, n. 2 , p. $436-443,2000$

EUROPEAN WEED RESEARCH COUNCIL - EWRC. Cite of methods in weed research. Weed Res., v. 4, n. 1, p. 88, 1964.

GEALY, D. R. et al. Gene flow between red rice (Oryza sativa) and herbicide-resistant rice (O. sativa): implications for weed management. Weed Technol., v. 17, n. 3, p. $627-645,2003$.

INSTITUTO RIO GRANDENSE DO ARROZ - IRGA. Arroz: Rio Grande do Sul cumpre seu papel. Lav. Arroz., v. 56, n. 446, p. 6-19, 2008.
KISSMANN, K. G. Resistência de plantas a herbicidas. São Paulo: Basf Brasileira, 1996. 96 p.

KUK, Y. I.; BURGOS, N. R.; SHIVRAIN, V. K. Natural tolerance to imazethapyr in red-rice (Oryza sativa).

Weed Sci., v. 56, n. 1, p. 1-11, 2008.

MENEZES, V. G. Sistema "Clearfield" de produção de arroz: uma nova alternativa no manejo de arroz vermelho. In: CONGRESSO BRASILEIRO DE ARROZ IRRIGADO, 3.; REUNIÃO DA CULTURA DO ARROZ IRRIGADO, 25. 2003, Itajaí. Anais... Itajaí: EPAGRI, 2003. p. 824-826.

RAJGURU, S. N. et al. Mutations in red-rice ALS gene associated with resistance to imazethapyr. Weed Sci., v. 53, n. 2, p. 567-577, 2005.

RAMÍREZ, H. B. Polinização cruzada em arroz irrigado. 2003. 125 f.Tese (Doutorado em Agronomia - Ciência e Tecnologia de Sementes) - Universidade Federal de Pelotas, Pelotas, 2003.

RIZZARDI, M. A. et al. Aspectos gerais do manejo e controle de plantas daninhas. In: VARGAS, L.; ROMAN, E. S. (Eds.). Manual de manejo e controle de plantas daninhas. Bento Gonçalves: Embrapa Uva e Vinho, 2004. p. 105-144

SHIVRAIN, V. K. et al. Gene flow between Clearfield ${ }^{\mathrm{TM}}$ rice and red-rice. Crop Protec., v. 26, n. 3, p. 340-356, 2007.

SOCIEDADE SUL-BRASILEIRA DE ARROZ IRRIGADO - SOSBAI. Arroz irrigado: recomendações técnicas da pesquisa para o Sul do Brasil. Pelotas: Sosbai, 2007. 164 p.

VIDAL, R. A. et al. Definindo resistência aos herbicidas. R. Plantio Direto, v. 100, n. 1, p. 18-19, 2007.

VIDAL, R. A. et. al. Resistência de Eleusine indica aos inibidores de ACCase. Planta Daninha, v. 24, n. 1, p. 163-171, 2006.

VILLA, S. C. C. et al. Arroz tolerante a imidazolinonas: controle do arroz-vermelho, fluxo gênico e efeito residual do herbicida em culturas sucessoras não-tolerantes. Planta Daninha, v. 24, n. 4, p. 761-768, 2006. 